\title{
Auroral and Sun-spot Frequencies Contrasted
}

This content has been downloaded from IOPscience. Please scroll down to see the full text. 1906 Proc. Phys. Soc. London 20434

(http://iopscience.iop.org/1478-7814/20/1/331)

View the table of contents for this issue, or go to the journal homepage for more

Download details:

IP Address: 131.215.225.9

This content was downloaded on 03/10/2015 at 22:30

Please note that terms and conditions apply. 
with altemating and direct currents. The alloy selected was ferro-nickel, as it was expected that this would show the effect strongly, as the constituents give a strong themoelectric E.M.F. A current was sent through a long ferronickel wire doubled back on itsolf, and this current was measured by a Kelvin balance, while the voltage on the ends of the wire was mensured by a Kolvin electrostatio voltmeter

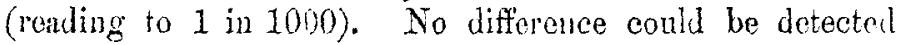
between the apparent resistance with direct current and with alternating current of frequencies up to 80 per second (the usual correction for contact difforcnce being found and applied).

Mr. W. Denoere suggested that the Author should proceed with his experiments asing rery mach higher frequencies.

\section{Auroral and Sun-spot Frequencies Contrasted. By C. Chres, So.D., LL.D., K.R.S.*}

\$1. DURIsG several recent investigations thave had occasion to contrast the annual variation in years of many and in years of few sum-spots of elements such as the diumal ringe of the magnetic declination, or the frequency of occurrence of magnetic storms. The formula first advanced by Wolf

$$
\mathrm{R}=a+b \mathrm{~S} \quad \text {. . . . . . }
$$

as connecting $R$, the range in the mean diumal inequality of declination thronghout the year, with $S$ the corresponding sun-spot frequency-a and $b$ being constants-can be appilied with considerable accuracy to the range in individual months of the year, and to magnetic inclination, horizontal force and vertical force, as well as declination. But taking any one element, and $b$ are different for the different month of the year, and $b / a$ is in general decidedly larger for winter than for summer.

Suppose, now, that lashed letters refer to a winter, nndished to a summer month, and that suffixes 1 and 2 relate

* Rearl Novemher 23, 7006 . 
to two years in which sun-spots are respectively many and few. Then for the ratio of the ranges in the summer and the winter month concerned, we have in the year of many sun-spots,

$$
R_{1} / R_{1}^{\prime}=\left(a / a^{\prime}\right)\left(1+\frac{b}{a} S_{1}\right) \div\left(1+\frac{b^{\prime}}{a^{\prime}} S_{1}\right)
$$

supposing for simplicity the sun-spot frequency the same for the two months. On the same hypothesis, we lave for the corresponding ratio in the year when sum-spots are few,

$$
R_{z} / R_{2}^{\prime}=\left(a^{\prime} a^{\prime}\right)\left(1+\frac{b}{a} \mathrm{~S}_{2}\right) \div\left(1+\frac{b^{\prime}}{a^{\prime}} \mathrm{S}_{2}\right)
$$

From these two equations we at once deduce

$$
\frac{\left(R_{2} / R_{2}{ }^{\prime}\right)-\left(R_{1} / R_{1}{ }^{\prime}\right)}{R_{1} / R_{1}^{\prime}}=\left(\begin{array}{l}
p^{\prime} \\
a^{\prime}
\end{array}-\frac{l}{a}\right)\left(S_{1}-S_{2}\right) \div\left\{\left(1+\frac{b}{a} S_{1}\right)\left(1+\frac{{ }^{\prime}{ }^{\prime} \mathrm{S}_{2}}{a_{2}}\right)\right\}
$$

As alrealy mentioned, observation shows that $l^{\prime} / a^{\prime}$ exceeds b/a, and by hypothesis $S_{1}-S_{2}$ is positive, thus

$$
R_{2} / R_{2}{ }^{\prime}>R_{1} / R_{1}{ }^{\prime} \text {. . . . . . }
$$

In temperate latitudes, whether sun-spots be many or faw, the diurnal range of any magnetic element is larger in stmmer than in winter, i.e. $R_{1}$ exceeds $R_{x}{ }^{\prime}$ and $R_{2}$ exceeds $R_{2}$. Thus (2) shows that relatively considered the diurnal range is more variable throughout the year when sun-spots are few than when they are many. In other words, if the annual change of the diurnal range be illustrated by a curve whose ordinates represent the ratios borne by the ranges in individual months to their arithmetic mean for the twelve months, the maximum and minimum ordinates differ more when the year selected is one of few than when it is one of unany sun-spots.

\$2. Again, taling a list of the more considerable magnetic disturbances recorded at Greenwich from 1848 to 1903 , as given by Mr. W. Maunder, I obtained the following figures* for the relative frequency at different seasons of the year, treating scparately the fourteen years of largost ( $S$ max.) 
and the fifteen years of smillest (S min.) sun-spot frequency:

Winstr.

November to February.

S nux. S min.

$35 \quad 28$
Eerinox.

Murch, April, Sept. Oct.

S max. S mil.

38

\section{Summar.}

May to Augrust.

$S$ minx. S min.

$27 \quad 24$

The figures denote percentages of the totals for the whole yoar. The average absolute numbers of storms per ammum were

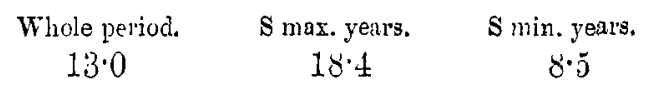

With increased sum-spot frequency, the absolute number of storms increased in all three seasons of the year ; but relatively considered the increase was least in the equinoctial montlis - the season when magnetic storms are most numerous at Greenwich-and the tendency abviously was towards a more unitorm distribution throughont the year. The phenomenon is thus analogous to that described above in the caso of the regular diumal range.

§3. In temperate latitndes, as is woll known, magnetic storms of any considerable intensity are usually associated with auroras. It was thus of interest to determine whether auroral frequency showel phenomena corresponding to those just described in l'errestrial Magnetism. It has long been known that auroral frequency, as observed in temporate latitules, varies in a general way with sun-spot frequency. The results obtained, however, have not shown a very exact correspondence between the years of maximum and minimum in the two classes of phenomena. In the case of sun-spot frequency-except as regards data for recent yenrspractically the only source available has been the data pullished by Wolf and Wolfer, which extend buck to 1749 . It is improbable that the unit in Wolfer's latest tablo * ropresents an absolutely unchanging value throughout the wholo period, but great care has been taken to make the table as homogeneous as possible, and the epochs it gives for the occurrence of sun-spot maximum and minimum are presumably, in at least the great majority of cases, very approsimately correct.

* Wet. Zcit. 1902, rul. xix. p. $19 \overline{5}$. 
Auroral data are exposed to many moro uncertainties. The observed frequency varies enormously at different parts of the Eirth, and the number of auroras recorded in any specified area is largely dependent on the provision made for observing and recording them. Conspicuous auroras are unlikely to escape notice in populous countries where they are rare occurrences, but in Arctic latiludes where auroras are common many doubtless fail to be recorded. With the increase of population and the dyvelopment of means of communication characteristic of the last 1 no yeurs, there has no doubt been a tendency to an increase in the proportion of auroras which come to be recorded.

Thus auroral frequency is a quantity which is certainly not expressed in terms of an invariable unit; and the various tables which have been published show irregularities duo to temporary and local causes, whose disturbing influence it is practically impossible to assess. In the following investigations the methods adopted aim at reducing to a minimum the effect of the various uncertainties.

$\S 4$. The sun-spot frequencies male use of are deriverl exclusively from Wulfer's table, which gives data for cach indivichal month during the 153 years 1749 to 1901 . The auroral frequencies are from two sources, viz.: "Catalog der in Norwegen bis Juni 1878 beobachteten Nordlichter" zusammengestelit von Sophus Tromholt, heransgegeben von J. Fr. Schroeter" (Kristiania, 1902), and Joseph Lorering's "On the Periodicity of the Aurora Borcalis" (Mem. Americun Acndemy, New Series, vol. x. 1868).

Of the several tilbles in the former work, that employed is Tablo $\mathrm{E}, \mathrm{pp} .411-417$, which gives anroral frequencies derived from the whole of Scandinavia from July 1761 to June 1878. In this table Schroeter has combined 'Tromholt's results for Norway with those of Rubenson for Swerlen. In the original the yearly totals are for years commencing in July. In order, however, to obtain results more strictly comparable with Wolfer's mean annual sun-spot frequencies, I have calculated from the Scaudinavian monthly totals data for years commencing in January. In addition to yearly totals-from July to June-for the whole of Scandinavia, 'Tromholt's 'Table E gives yearly totalis for five subdivisions 
of the country, numbered $I$. to $V$. according to latitude. T. includes all districts north of $68^{\circ} .5$, II. extends from $68^{\circ} \cdot 5$ to $65^{\circ}$, III. from $65^{\circ}$ to $61^{\circ} 5$, IV. from $61^{\prime} \cdot 5$ to $58^{\circ} \cdot 5$, while $V$. includes the extreme south of Scandinavia from $58^{\circ} .5$ to $55^{\circ}$.

For a consilerable tim 3 subsequent to 1761 , observations from district $I$. were very few, a fact due probably more to lack of observers than anything else. This possesses some inportance for the fo!lowing reason. The annual variation in auroral frequency is largely dopendent on the fact that aurora is seldom vivid enough to be visible until the sun is several degrees below the horizon. In high latitudes there is daylight throughout the whole 24 hours near midsummer, and no daylight near midwinter, and the auroral frequency in these regions, as was pointed out many years ago by Lovering, has a single maximum near midwinter, and a single minimum answering to a total absence of aurora near midsummer*. This state of matters is at least approached in district I., and to a lesser extent in district II. (cf. loc. cit. Table G, p. 420). Further south in Scandinavia the annual variation is similar to that in England, showing two maxima near the equinoxes, a principal minimum at midsummer, and a secondary minimum at midwinter. The mean annual variation deduced for the whole of Scandinavia will clearly depend to some extent on bow far the several districts contribute to the general result. Assuming an increasing relative contribution from district $I$., if annual variations be calculated from two different periods, one may not unreasonably expect the later period to show the equinoctial maxima less prominently and the midsummer minimum more prominently than the earlier period. This is one of my reasons for contrasting one period of a special type with two of an opposite type, the one carlier the other later.

Lovering gives annual variations for a number of separate stations. Most of these, however, are based on too few year's' observations to suit the present enquiry.

Of the dita for separate stations or districts, I propose to use only those for New York State (l.c. p. 181). These extend over 26 years, including 1205 senarate observations, * (f. A. Antet's ' Lez Aumores Poldires, Paris, 1805, p. 125. 
and represent a latitude much lower than that of Seandinavia. The other data employed are from Lovering': General Catrague, pp. 195-200. This comes down to 18it, and extends to earlier than the 14th century. Thongh enumerating nearly 10,000 anroms it is probably, judging by Trombolt's figures, very far from complete. Tho ditin are doubtless of a very heterogeneous charactor, and tho same precantions appeared necessary as in the case of the Scandinavian data.

Recently Prof. Schuster* has gone very fully into the existence of periodic variations in Wolfer's sum-spot frequencies, and has concluded that there is eridence of the existence not merely of the ordinarily recognized period of 11.125 years, but of others which like it are submultiples of a period whose most probable value is 33375 years. This is one of the reasons why I have lealt with three successive 33-year periods, viz. 1761-1793, 1791-1826, and $1827-1859$.

$\$ 5$. Before comparing sun-spots and auroras, I would draw attention to some feitures of Table $I$, which gives mean stinspot frequencies for the several montls of the year, as caleulated by me from Wolfer's table for a number of specified combinations of years. It has been remarked by Mr. Ellis $\dagger$ -who based his remarks on Wolfer's datil for groups of 3 months (February to April, \&c.) - that sm-kpot frequency shows no real annual period. The results in the first line of Table I. cannot be said to be decisive against the existence of a small annual term, though inconsistent with the existence of a large term having this periol. Tho extent of the difference between the mean results for the several months is more easily realized in Table 11., which expresses the monthly values in Thble I. as jercentages of the arithuctic mean for the 12 months. One would, I think, harlly have nutivipated, in means based on 150 years data, the difference of $6 \frac{1}{2} \mathrm{per}$ cent. shown between the vahnes for January and May. On the otber hand, if there were a true ammal period, one wonlh expect the percentage figures in Table II. for the three

* Proe. Roy, Suc. A. wh lexrii. p. 145 .

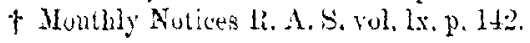

ror, $\mathrm{xx}$. 


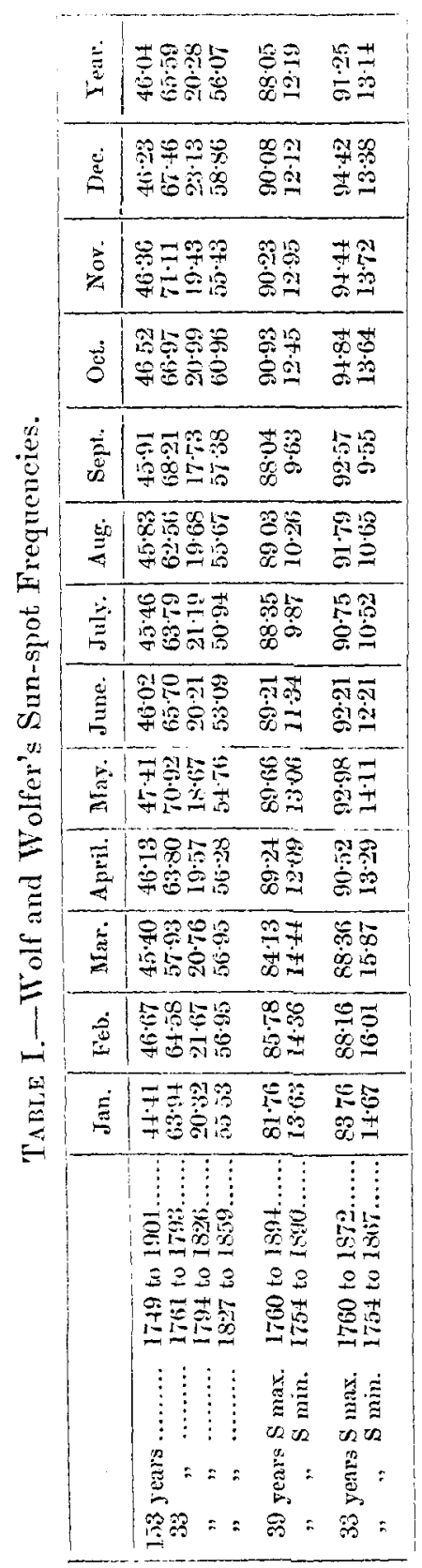

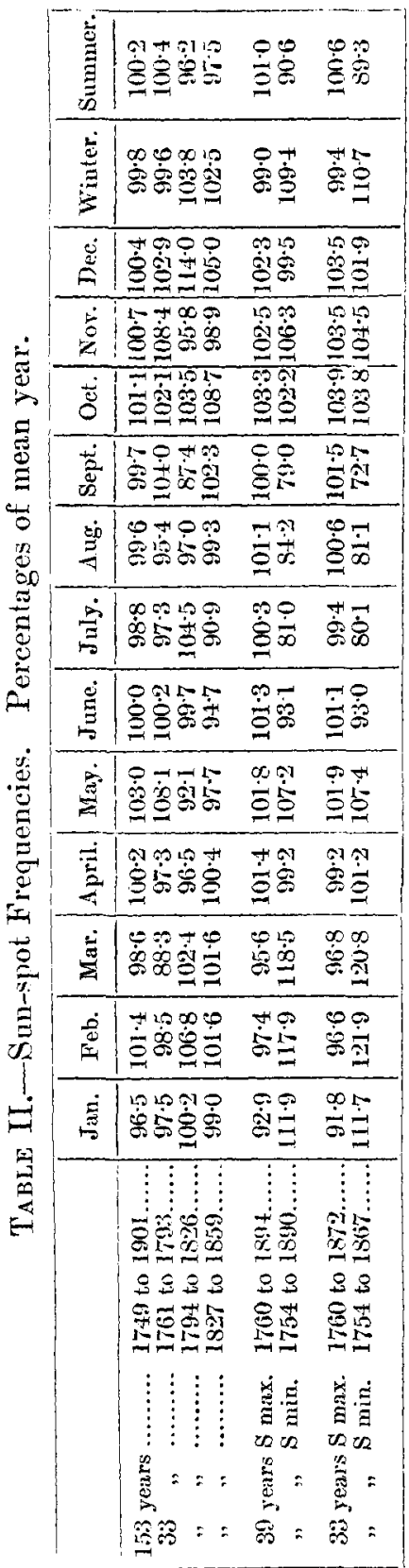


successive 33-years periods to resemble one another more closely than they actually do.

The monthly means in these three periods show very considerable differences ; in the earliest period, for instance, the difference between the March and November means amounts to 20 per cent. of the mean value for the epoch.

The central period 1794-1826 comprises that period of 33 consecutive years which gives a minimum mean sur-spot frequency. That mean is only a third of the mean appropriate to the combined periods $1761-93$ and $1827-59$.

As a rule, three successive years of conspicuously high frequency occur at each sun-spot miximum, and three of conspicuously low frequency at each minimam. Wolfer's table includes 13 groups of these 3 extreme years of sun-spot maximum, and 13 of sun-spot minimum. The respective means from these 39 years of maximum and 39 years of minimum form the fifth and sixth rows of Tiables I. and IT. The last two lines in these Tables refer to shorter groups of 33 years of sun-spot maximum and 33 of minimum which correspond more closely to the auroral data presently to be described.

\$6. Probably the simplest way of investigating the relationship between sun-spot frequency and the magnitude. of any element is to form two mean values for the element, the one corresponding to years of many, the other to years of few sun-spots, and then to assume that the difference betweon these means depends on the corresponding difference in sullspot frequency. In applying this method to data from the whole period covered by Wolfer's table, one would employ the sun-spot frequencies given in the 5th and 6 th rows of Table I. Doing so, we should get differences of sun-spot frequency varying from $81 \cdot 76-13 \cdot 63$, or $68 \cdot 13$, in January, to 78.77 in August. The existence of so large a difference between the sun-spot data for January and August is immaterial, provided there is a direct connexion, which possonsen no lag, between sun-spot frequency and the element concernetl. If, however, the connexion is of a less simple charater, for instance if the element depends on the sun-spot frequency for some months previously, the application of the above method would leard to an overestimate of the influence of 


\begin{tabular}{|c|c|c|c|c|c|c|c|c|c|c|}
\hline 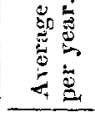 & ${ }_{i=1}$ & $\overrightarrow{0}$ & $\ddot{\vec{D}}$ & $\stackrel{\dot{\mathscr{C}}}{\dot{\mathscr{C}}}$ & $\stackrel{10}{8}$ & $\vdots$ & $\overrightarrow{0}$ & $\stackrel{\vec{\partial}}{\ddot{\theta}}$ & $\stackrel{D}{:}$ & $\underset{i}{\infty}$ \\
\hline 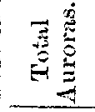 & $\stackrel{2}{3}$ & $\frac{53}{9}$ & $\vec{\infty}$ & 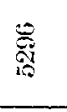 & 荡 & 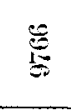 & $\frac{\overline{9}}{3}$ & $\stackrel{9}{h}$ & กี & 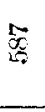 \\
\hline 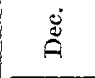 & $\stackrel{\oplus}{\oplus}$ & $\begin{array}{l}\infty \\
\infty \\
\infty \\
\infty\end{array}$ & 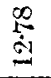 & $\stackrel{\mathscr{9}}{\rightleftarrows}$ & 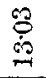 & 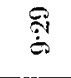 & $\stackrel{19}{i}$ & $\stackrel{\ddot{*}}{\ddot{7}}$ & $\overline{\grave{\grave{c}}}$ & 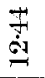 \\
\hline 量 & 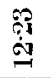 & $\stackrel{\overrightarrow{5}}{\Xi}$ & $\stackrel{g}{9}$ & $\stackrel{8}{\stackrel{0}{=}}$ & $\stackrel{g}{ \pm}$ & $\stackrel{5}{5}$ & $\frac{1}{\infty}$ & $\stackrel{\infty}{\Leftrightarrow}$ & $\stackrel{8}{8}$ & $\stackrel{g}{\stackrel{g}{0}}$ \\
\hline ثُ & 羿 & 产 & 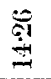 & 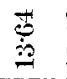 & 罢 & $\stackrel{5}{=}$ & 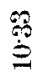 & $\stackrel{\text { 菏 }}{\leftrightarrows}$ & 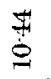 & $\frac{8}{\dot{S}}$ \\
\hline 范 & $\stackrel{10}{=}$ & $\stackrel{5}{\stackrel{5}{\sharp}}$ & $\stackrel{b}{=}$ & $\stackrel{\hat{b}}{\hat{\theta}}$ & $\frac{0}{b}$ & $\stackrel{\mathscr{P}}{\stackrel{\theta}{\theta}}$ & $\stackrel{\vec{N}}{\Theta}$ & 8 & 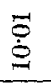 & $\underset{i}{\infty}$ \\
\hline$\stackrel{\dot{y}}{g}$ & $\stackrel{\vec{q}}{\vec{d}}$ & $\stackrel{m}{\oplus}$ & $\stackrel{0}{\dot{\theta}}$ & $\stackrel{8}{\not{4}}$ & 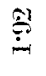 & 焉 & $\stackrel{\vec{\theta}}{\dot{\Gamma}}$ & $\stackrel{\infty}{0}$ & $\stackrel{0}{0}$ & $\begin{array}{l}\infty \\
\stackrel{\infty}{\infty}\end{array}$ \\
\hline$\stackrel{\dot{\Xi}}{\Xi}$ & : & 8 & $\frac{\infty}{b}$ & 丞 & $\stackrel{\infty}{0}$ & $\hat{i}$ & 焉 & 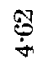 & 38 & $\stackrel{9}{\dot{\varphi}}$ \\
\hline$\stackrel{\Xi}{\Xi}$ & $\stackrel{+}{0}$ & $\stackrel{\infty}{b}$ & छ̊̊ & $\dot{0}$ & $\$$ & 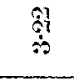 & $\stackrel{5}{\dot{t}}$ & is & क्ञ & 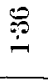 \\
\hline 㻤 & $\stackrel{9}{9}$ & $\underset{\sim}{\mathscr{S}}$ & $\frac{9}{5}$ & $\underset{\rightarrow}{\stackrel{T}{-1}}$ & $\vec{\varphi}$ & $\underset{8}{0}$ & 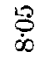 & $\stackrel{5}{\stackrel{5}{\sigma}}$ & 怘 & $\stackrel{a}{a}$ \\
\hline 苞 & $\frac{8}{60}$ & $\stackrel{\vec{c}}{\dot{c}}$ & $\vec{b}$ & $\underset{\dot{\infty}}{\mathscr{O}}$ & $\stackrel{9}{9}$ & $\begin{array}{l}5 \\
6 \\
0\end{array}$ & $\stackrel{9}{\stackrel{9}{=}}$ & $\stackrel{+}{\infty}$ & 10 & $\stackrel{⿱ 艹 冖}{=}$ \\
\hline 苛 & $\stackrel{\infty}{\stackrel{\infty}{\circ}}$ & $\stackrel{1}{0}$ & $\underset{5}{5}$ & $\underset{d}{i}$ & $\stackrel{5}{ \pm}$ & $\stackrel{\mathscr{O}}{=}$ & $\underset{ت}{ت}$ & $\stackrel{+1}{\mathscr{S}}$ & $\stackrel{\substack{0 \\
0}}{0}$ & 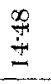 \\
\hline تُ & $\stackrel{\infty}{=}$ & $\stackrel{19}{9}$ & $\stackrel{g}{ \pm}$ & $\stackrel{g}{:}$ & $\stackrel{g}{+}$ & $\dot{\omega}$ & $\frac{\vec{\infty}}{\infty}$ & $\overrightarrow{0}$ & $\underset{\infty}{\infty}$ & $\bar{Z}$ \\
\hline 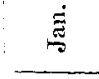 & $\stackrel{9}{9}$ & 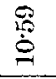 & 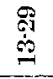 & $\stackrel{\vec{g}}{=}$ & 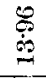 & 㻤 & $\vec{\infty}$ & $\overrightarrow{0}$ & $\bar{a}$ & $\begin{array}{l}i 2 \\
\dot{\theta}\end{array}$ \\
\hline & 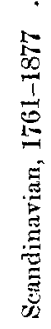 & $\frac{n}{20}$ & 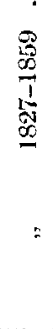 & 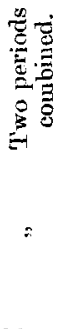 & $\begin{array}{l}0 \\
0 \\
0 \\
\frac{1}{6} \\
0\end{array}$ & 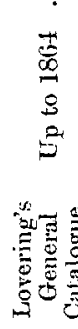 & 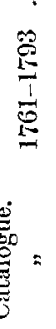 & $\begin{array}{l}5 \\
3 \\
30 \\
5 \\
5 \\
0 \\
0 \\
0\end{array}$ & 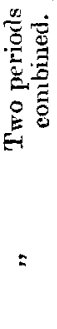 & 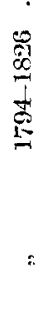 \\
\hline
\end{tabular}


sun-spot frequency in January and an underestimate in August. If we use more exact methods, $e$. g. the method of least squares, - still assuming purely synchronous variationthe above source of uncertainty is less easily recognized, but it exists all the same. Considered absolutely, the difference between the mean monthly values in Table $I$. is greater for the 39 or the 33 years of $\mathrm{S}$ max. than for the corresponding group of $\mathrm{S}$ min. years; but relatively consideredcf. Table II.- the variability from month to month is greater for the $\mathbf{S}$ min. group. Thus in the 39 years of $\mathbf{S}$ min. the means for March and Septemler differ by 39 per cent. of the mean from the 12 months. Moreover in the $\mathrm{S}$ min. grouls of years there is a decided difference-some 20 per cent.botween the means derived from the 6 winter and the 6 summer months. There is a smaller difference, but in the same direction, hetween the winter and summer means from the 33-year period 1794-1826 remarkable for its low average sun-spot frequency. This is unquestionably somewhat sncgestive of an appreciable real annual period in sun-spot frequency in years when sun-spots are few; but whereas in the 39 or 33 years of $\mathrm{S}$ min. the mean frequency is large for May and November, and small for July, in the period 1794-1826 the exact opposite is seen. Again, an appreciable excess in the winter over the summer mean also appears in the period $1827-59$, when the average sun-spot frequency considerably exceded the avcrage from the whole 153 years.

\$7. Proceeding to Table III., we have in the first line the annual variation of auroral frequency in Scandinavia as derived from 117 years. The monthly values represent percentages of the value for the whole year. The largest values occur in October and March, and a secondary minimum is recognizable in December. The dip in the February value arises really from the smaller number of days in that month. When referred to an equal number of days, the Fehruary frequency exceods that in Jamuary in the ratio of $104: 100$.

In the second and third lines we have similarly annual variations from the two 33-year periods of ligh average sun-spot frequency, their mean appearing in the fourth line. 
For the ratio, however, between the menn frequencies from the entier and from the later of these two periods we have

$$
\begin{array}{cc}
\text { From Sin-spots. } & \text { From Auroras. } \\
100: 85 & 100: 111 .
\end{array}
$$

If we contrasted these two periods with one another we should thus associnte an increase in auroras with a diminntion in sun-spots.

Again, the ammal variations from the two periods differ markedly. In the later period, as compared to the earlier, the summer frequencies fall and the winter frequencies rise.

The differences apparent between the two periods may represent a real change, but in all probability they are largely due to an increase in auroral observers, especially in the northern districts of Scandinavia. Taking the yearly data for the five districts mentioned above, we obtain for the total number of auroras observed the results given in Table IV.

\begin{tabular}{|c|c|c|c|c|c|c|}
\hline & \multicolumn{5}{|c|}{ District. } & \multirow{2}{*}{ All } \\
\hline & I. & II. & III. & IV. & v. & \\
\hline \multicolumn{7}{|l|}{ July to June. } \\
\hline 1761 to $1794 \ldots \ldots \ldots \ldots$ & 22 & 293 & 970 & 14503 & 555 & 2481 \\
\hline 1794 to $1827 \ldots \ldots$. & 52 & 694 & 408 & 518 & 56 & 1316 \\
\hline 1827 to $1860 \ldots \ldots \ldots \ldots$ & 827 & 873 & 352 & 1531 & 473 & 2811 \\
\hline 1st \& 3rd periods combined. & 849 & 1166 & 1322 & 2984 & 1028 & 5292 \\
\hline
\end{tabular}

TAJIXS IV.-Amrom Observations in Scandinavia.

An aurora is often seen in more than one district, but comparatively seldom in all. Obviously the increase in the aurornl frequency in the latest as compared to the earliest of the three periods arises from the large increase of observations in the two most northern districts; and this being so, the tendency naturally is to bring the annual frequency nearer to the Arctic type with a single maximum at midwinter.

Coming now to the intermediate period in Table IV., we see that the development of district I. was mainly subsequent to 1827. Thus what we should a prioni expect to observe in 
the annual variation from this period in Table III. would be a form intermediate between those from the other 33-year periods, but approaching most closely that from the earlier period. What we actually do find is a variation differing from that of 1761-93 in the expected direction, but to an even greater extent than does the variation from the period 1827-59. Comparing the results from 1794-1826 in Table III. with the means from the preceding and sncceeding 33-year periods we largely eliminate the inflnence of the change in observational conditions. The figures show that in the 33-year period characterized by fev sun-spots, summer occurrences of aurora were relatively much fower and winter occurrences more numerous than in the aljacent 33-year periods of high arerage sun-spot frequency. We thus have low sun-spot frequency associated with an exaggeration in the annual variation of auroras, the precise phenomenon already described in connexion with T'errestrial Magnetism.

\$8. The mean sun-spot frequency for the two 33-year periods 1761-93 and 1827-59 combined was 60.83 , whilst the corresponding auroral frequency for the year was $80^{\circ} 2$.

Comparing these with the corresponding figures for 17941826 , we have for a trebling of sim-spot frequency only a doubling of auroral frequency. This would suggest that if auroral frequency is connected with that of sun-spots by a formula of type (1), then the constant a does not vanish; i. e., a total absence of sun-spots would not be accompanied by a total absence of auroras. A difficulty, however, arises here, which the figures in lable IV. for the several districts of Scandinavia will serve to explain.

The ratio borne to the frequency of auroras in the average year of the period $1794-1827$ by the corresponding frequency for the combined periods $1761-94$ and 1827-60 is roughly $2: 1$ for the whole of Scandinavia ; but is $9: 1$ for district $V$., $3: 1$ for district IV., $3: 2$ for district III., and less than $1: 1$ for district II. Any comparison for district I. would be misleading.

These figures suggest that with decrease in sun-spot frequency the diminution in auroral frequency is enormously greater in the south than in the morth of Scandinavia. 
Several authorities have called attention to analogous phenomena, and the theory has even been adranced that the difference in auroral frequency in years of many and fow sun-spots renlly arises from the alternate expansion and contration of Fritz's isochasins* (curves of equal auroral frequency). The thaory does not seem to be strongly supported, but there seems little if any doubt that a substantial difference really exists between the long period changes of anroral frequency in different regions. Results from several stations in Greenland-whose substantial accuracy seams accepted by Prof. A. Paulsen, one of the leading authorities on the subject-appear to inlicate that auroral frequency is there very considerably less when sun-spots are many than when they are few.

\$ 9. We now pass to the consideration of the figures from Lovering's general catalogue in the last five lines of 'Table III. As before, the monthly figures are expressed as percentages of the yearly total. The figures corresponding to the whole period covered by the table are given by Lovering $t$ himelf. "Though derived from very beterogeneous data, they represent very fairly the type of amnual variation which is characteristic of lower temperate latitudes. The midsummer minimum and the equinoctial maxima are less pronounced than they are even in the Sonth of England.

Comparing the totals from the two periods 1761-93 and $1627-59$, we see that the excess from the later period is even greater than it was in the case of Scandinavia. The annual rariations from the two periods also differ, and in the same direction as before. From May to September the relative frequency is decidedly less, and at midwinter considerably greater, for the later period than for the earlier, ard the equinoctial maxima are but indistinctly shown in the later perior. As in the case of Scandinavia, northern stations may have contriluted more to the means for 1827-5) than to thase for 1761-13. It is clear, however, from the substantial frectrencies in the summer months, that even in the period

* Cf. Anport, 'Jes Aurores lolaires,' p. 138.

$\dagger$ L. c. 1]) 200 \& 216 . 'The total for' December on p. 200 should npinently besor, and not 1007 as printed. 
1827-5y dala from temperate latitudes must largely have frevailed. Thus the closer approach to the Arctic or single maximnm type is difficult to wholly explain, unless we admit that it is partly a real phenomenon, representing a real difference in the distribution of auroras throughout the average year of the two periods $1761-93$ and 1827-59. As regards the intermediate periol 1794-1826, we see that its mean amual variation diffed from that of the neighbouring periods in the sume direction as it did in the case of Scandinavia. The fall in the summer frequencies is very pronounced, even as compared to the period 1827-59 alone. Of the equinoctial maxima, that in Mareh is much enhanced, but that in October seems to have vanished, unless it is represented by the maximun now shown in December.

The average year from the two periods $1761-93$ and 1827-59 combined show fully fire times the auroral frequency of the average year of the period 1794-1826. This is intermediato between the ratios deduced for the Scandinarian districts IV. and V.

$\$ 10$. Table $V$. shows the amnual variation of auroral frequency in several pairs of groups of years characterized respectively by many and by few sun-spots. The first line gives results for the whole of Scandinavia from 30 years, micle up of the 3 years of largest sun-spot frequency from each of the ten 11-year cycles covered by Trombolt's table; the second line gives the results for the corresponding 30 years of fow sun-spots. Any gradual change in the nature of the observations should affect the two sets of results nearly oqually. The third and fourth lines givo corresponding datal calculated from Lovering's general catalogue, also for 30 years of many and 30 years of few sun-spots.

of the ten 11-year cycles employed in the two cases nine are identical; the Lovering data cover one cycle prior to the common nine, the Scandinavian one later. This was unfortunately necessary owing to the dates when the Lovering taljle ended and the complete Scandinavian table commenced. The two sets of data combined represent eleven consecutive 11-year cycles, and the sun-spot data for the 33 years of many and the 33 yeurs of tew sum-yots from these cleven cycles 


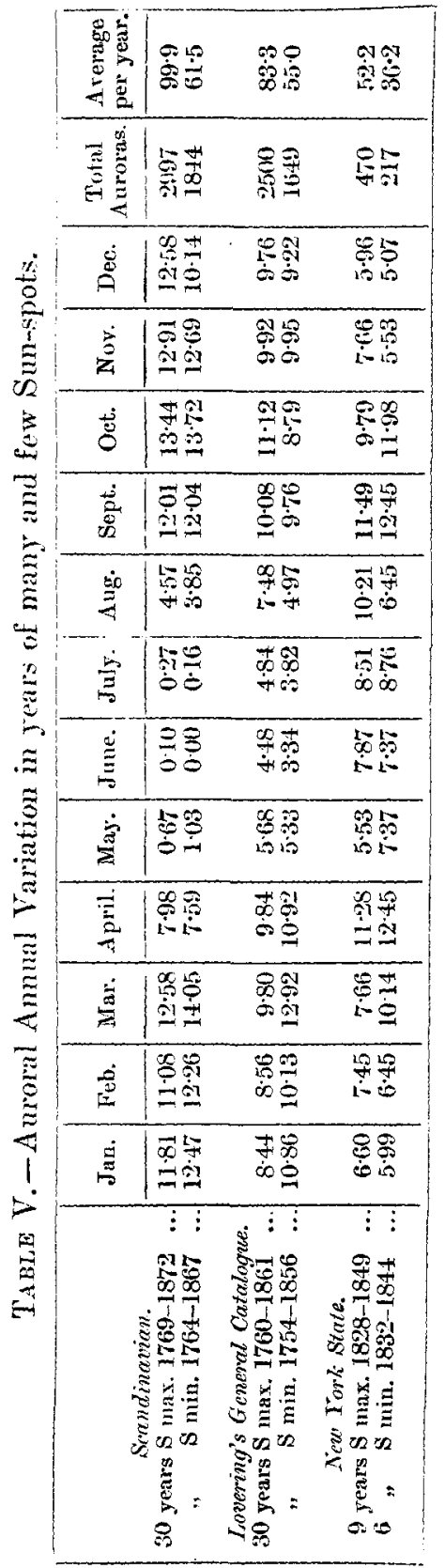

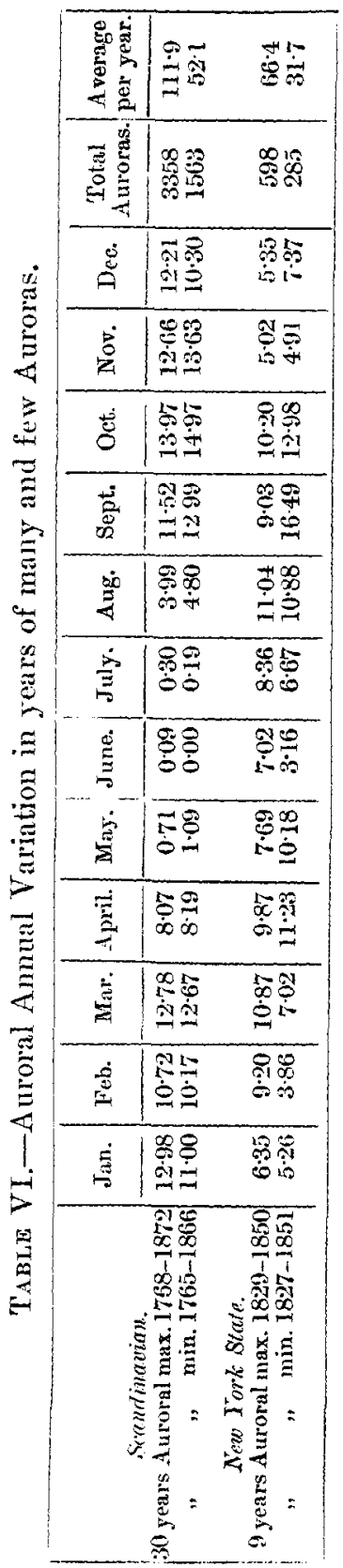


are those given in the last two lines of Tables I. and II. For the purposes of the present enquiry, these sun-spot datit answer sufficiently closely to either the Scandinavian or the Lovering auroral data.

The last two lines of Table V. give auroral data for New York State, derived from $3 \times 3$ years of largest sun-spot frequency and $2 \times 3$ years of least sun-spot frequency included between 1828 and 1849 .

Each of the three pairs of comparative figures in Table V. shows a decided rise in the spring maximum in the years of few as compared to the years of many sun-spots.

The average monthly frequency from May to August is also less in the years of few sun-spots, very decidedly so in the case of Lovering's data; in the New York data the depression of the midwinter minimum is the more decided. On the whole, the phenomena resemble those already described, $i . e$. the annual variation is accentuated in the years of few sun-spots. The differences, however, between the selected years of many and the selected years of few sunspots are less conspicuous than those beiween the 33-year periods; and such differences as exist may not unreasonably be partly ascribed to the differences in the annual variations of the sun-spot figures in the last two lines of Tables I. \& II. This explanation cannot, at the same time, go very far, in view of the fact that there is no marked depression in the aturoral frequency in September in the groups of 30 yenrs of few sun-spots.

The differences between the average number of auroras in the year from the first two groups of contrasted years in Table V. are much less than the corresponding differences in Table III., notwithstanding that the sun-spot differences are larger in the case of Table $V$. The ratio of the mean frequency from the period or group of years of many sunspots to the corresponding frequency from the period or group of years of few sun-spots takes the following approximate values in the several cases (p. 450).

Obvionsly the conclusions one would draw as to the extent of the influence of sun-spot on auroral frequency would vary immensely according to one's method of attacling the froblem. 


\begin{tabular}{|c|c|c|c|c|}
\hline & \multicolumn{2}{|c|}{$\begin{array}{l}\text { From the 33-year periods. } \\
\text { 'Tables I. aud III. }\end{array}$} & \multicolumn{2}{|c|}{$\begin{array}{c}\text { From } 10 \times 3 \text { years of } \mathbf{S} \max \text { \& } \mathbf{S} \text { mint } \\
\text { Tables I. and } \mathrm{V} \text {. }\end{array}$} \\
\hline . & Sun-spot ratio. & Auroml ratio. & Sun-spot ratio. & Auroral ratio. \\
\hline Scandinavian duta.. & $3: 1$ & $2: 1$ & $7: 1$ & $1 \cdot 6: 1$ \\
\hline Lopering's data...... & $3: 1$ & $5 \cdot 5: 1$ & $7: 1$ & $15: 1$ \\
\hline
\end{tabular}

\$11. Table VI, deals with the same Scandinavian and Now York datin as the previous tables, but instead of selecting groups of 3 years of $\mathrm{S}$ max. and $\mathrm{S}$ min., it selected groups of 3 successive years of largest and 3 successive years of least anroral frequency. One of the groups for Now York State wils made up of the last and the two earliest years of the period of observation. The differences between the mean sun-spot frequencies for the contrasted groups of years in Table VI. are really much les: than in the corresponding cases in Tiable $V$., but the opposite is true of the mean auroral frequencies. For the ratio between the auroral frequencies in the contrasted groups of years we have 21:10 in Table VI, both for Sc.mdinavia and New York State, whereas in Table $V$. the corresponding ratios are respectively only $16: 10$ and $15: 10$.

As to annual variation in Tiable VI., the group of years of fow auroras shows, as complared to that of many auroris, an enhanced maximum at one or both oquinoxes, and a lower minimum both in winter and summer.

Lovering's general catalogue is not considered in Table VI. owing to the erratic way in which the auroral frequencies in it vary from year to year. In some of the 11-year cycles years of many and fow auroras seem to occur almost promiscuonsly, and the selection of 3 successivo years as representative of either high or low frer uoncy presented difficulties. Even in the comparatively homogeneous Scandinavian data, the sime phenomenon occurred to a certain extent.

$\$ 12$. The difference betweon the results in Tables V. and VI., and the great irregularity in the variations from year 
to year of auroral as compared to sun-spot frequency, point to one of two conclusions,--either

(1) Auroral data are so heterogeneous, or so intrinsically defective, that consecutire years' results are affected by large differential errors when treated as measures of the same quantity; or

(2) Auroral frequency depends, and to no small extent, on something more than the contemporaneors value of sun-spot frequency.

As to the question of a possible lig: In the case of Scandinavia the groups of 3 years selected from consideration of sun-spot frequency for use in Table $V$., ropresented an earlier epoch than those selected from consideration of anroral frequency for use in Table VI. in 14 cases, the same epoch in 2 cases, and a later epoch in only 4 cases. This is, to say the least, not unfiavourable to the view that auroral frequency tends to lag behind sm-spot frequency.

In every case we have found the annual variation in auroral frequency, monthly values denoting percentages of the total number for the year, to be more uniform when sunspots are numerous than when they are few. The differences, lowever, between the frequencies in the contristed years are in some instances not very conspicuons, and may be partly due to chance. Also, supposing it to be a fact that the annual variation in temperate latitudes becomos more accentuated as sun-spots diminish, this may mean one of two things. There may be, as sum-spots decrease, a greater relative diminution in summer than in winter of the physical phenomena which appeal to our eyes as aurora, or there may only be a general diminution in the brightness of aurous throughont the whole year. From what happens during magnetic storms, it can hardly be questioned that the cause - presumably electric discharges in the upper atmosuhereto which auroral phenomena are due is often active when aurora is invisible. It may even conceivably be in continuous operation, though incapable of appealing to the eye, however 


\section{AURORAL AND SUX-SPO'T FREQUEACIES CONTRASTED.}

favourable the visual conditions, until a certain minimum intensity is reached.

Only exceptionally brilliant auroras have much chance of being seen until the sun is far below the horizon so that a general reduction of intensity might well be more prejudicial to visibility at midsuminer than at other. seasons.

In conclusion, I should like to draw attention to the utility for investigations such as the present of trustworthy auroral observations taken on a uniform plan, desirably throughout more than one sun-spot cycle, at a considerable number of stations suitably distributed over the earth.

\section{Discussion.}

Dr. J. A. HARKer asked if in making calculations upon sun-spot frequencies any account was taken of the different sizes of spots.

Dr. Chres said the Astronomer Royal measured the areas of the spots, but Wolf used a "relative number" depending upon the total number of spots observed and upon the number" of groups and isolated spots. The two methods of estimating the sun-spot frequency agreed well. 